David W. Chapman

\title{
Ancient Jewish and Christian Perceptions of Crucifixion
}

[Die Wahrnehmung der Kreuzigung im antiken Judentum und Christentum.]

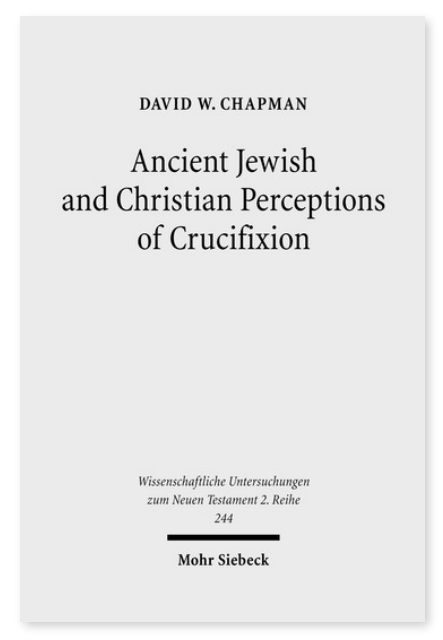

2008. XIII, 321 Seiten. WUNT II 244

ISBN 978-3-16-151587-3

DOI 10.1628/978-3-16-151587-3

eBook PDF 34,00€

ISBN 978-3-16-149579-3

fadengeheftete Broschur $34,00 €$
Veröffentlicht auf Englisch.

In der vorliegenden literarischen und archäologischen Studie untersucht David W. Chapman die differenzierten Wahrnehmungen über Kreuzigung im antiken und rabbinischen Judentum. Das frühe Christentum, welches einen gekreuzigten Messias verkündet, scheint sich dieser unterschiedlichen, jüdischen Auffassungen bewusst zu sein, da es negative Assoziationen verwirft, bzw. abändert und weiterführende Wahrnehmungen im Judentum aufgreift. Dabei wird deutlich, dass die frühe christliche Literatur über das Kreuz die unterschiedliche Wahrnehmung des Kreuzes in im antiken Judentum weit mehr als bisher angenommen widerspiegelt.

David W. Chapman Born 1966; 2000 PhD (University of Cambridge); since 2000 Professor of New Testament and Archaeology, Covenant Theological Seminary, Saint Louis, USA.

Jetzt bestellen:

https://mohrsiebeck.com/buch/ancient-jewish-and-christian-perceptions-of-crucifixion-9783161515873?no_cache=1

order@mohrsiebeck.com

Telefon: +49 (0)7071-923-17

Telefax: $+49(0) 7071-51104$ 